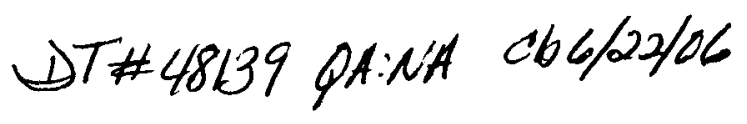

\title{
A Science-Based Approach to Understanding Waste Form Durability in Open and Closed Nuclear Fuel Cycles
}

MOL . 20060815.0149

\section{M.T. Peters* ${ }^{* 1}$, R.C. Ewing ${ }^{2}$}

1. Applied Science and Technology, Argonne National Laboratory, 9700 South Cass Avenue, Argonne, IL 60439 USA; mtpeters@anl.gov

2. Department of Geological Sciences, The University of Michigan, 2534 C.C. Little Building, 1100 North University, Ann Arbor, MI 48109-1005 USA; rodewing@umich.edu

\begin{abstract}
There are two compelling reasons for understanding source term and nearfield processes in a radioactive waste geologic repository. First, almost all of the radioactivity is initially in the waste form, mainly in the spent nuclear fuel (SNF) or nuclear waste glass. Second, over long periods, after the engineered barriers are degraded, the waste form is a primary control on the release of radioactivity. Thus, it is essential to know the physical and chemical state of the waste form after hundreds of thousands of years. The United States Department of Energy's Yucca Mountain Repository Program has initiated a long-term program to develop a basic understanding of the fundamental mechanisms of radionuclide release and a quantification of the release as repository conditions evolve over time. Specifically, the research program addresses four critical areas: a) SNF dissolution mechanisms and rates; b) formation and properties of $\mathrm{U}^{6+}$ - secondary phases; c) waste form-waste package interactions in the near-field; and d) integration of in-package chemical and physical processes. The ultimate goal is to integrate the scientific results into a larger scale model of source term and near-field processes. This integrated model will be used to provide a basis for understanding the behavior of the source term over long time periods (greater than $10^{5}$ years). Such a fundamental and integrated experimental and modeling approach to source term processes can also be readily applied to development of advanced waste forms as part of a closed nuclear fuel cycle. Specifically, a fundamental understanding of candidate waste form materials stability in high temperature/high radiation environments and near-field geochemical/hydrologic processes could enable development of advanced waste forms "tailored" to specific geologic settings.
\end{abstract}

Key Words: Nuclear Fuel Cycles, Geologic Disposal, Radionuclide Source Terms, Spent Nuclear Fuel, Waste Forms

\footnotetext{
*Corresponding author: tel: + 01-1-630-252-6511; fax + 01-1-630-252-5318

E-mail address: mtpeters@anl.gov .
} 


\section{Introduction}

There are two important reasons for understanding source term and near-field behavior. First, almost all of the radioactivity is initially in the waste form, mainly in the SNF and vitrified waste. Therefore, the waste form places the initial limits, as well as the longterm limits, on radionuclide release. Interactions of the source term with the near-field environment, such as the corroded waste packages, place additional constraints on the long-term behavior and mobility of radionuclides (cf. [1] and references therein; [2] and references therein). An enhanced understanding and realistic estimates of the extent to which radionuclides will be retained in the waste form or near-field environment reduce the demands on the performance of subsequent, far-field barriers. Realistic estimates of radionuclide release will also reduce the uncertainty in the total system performance assessment. Second, over long periods, after the engineered barriers are degraded, the waste form is a primary control on the release of radioactivity. Thus, it is essential to know the physical and chemical state of the waste form after hundreds of thousands of years.

The United States Department of Energy's Yucca Mountain Repository Program has initiated a long-term program to develop a basic understanding of the fundamental mechanisms of radionuclide release and a quantification of the release as repository conditions evolve over time. The goal of the source term research program is to enhance the understanding of the performance of nuclear waste forms (mainly SNF and nuclear waste glass) and to quantify the release of radionuclides in the evolving near-field environment expected at the proposed nuclear waste repository at Yucca Mountain. This program is directed at developing a basic understanding of the fundamental mechanisms of radionuclide release and a quantification of the release as repository conditions evolve over time, particularly at longer times $\left(>10^{5}\right.$ years). Radionuclide release will be sensitive to variations in the temperature, the radiation field, redox conditions, $\mathrm{pH}, \mathrm{p}_{\mathrm{CO}}$, surface area-to-solution volume, and the presence of near-field materials. Among the important processes that can control radionuclide release are: 1) the kinetics of waste form corrosion; 2) the formation of secondary, alteration phases; 3 ) the reduction and sorption onto the surfaces of near-field materials (see Fig. 1).

The prediction of the long-term behavior of nuclear waste forms cannot be based entirely on models of laboratory results that are extrapolated to long periods; hence, this program will integrate multiple lines of evidence (e.g., results from natural analogue studies) in order to clarify the scientific basis for waste form degradation mechanisms in relation to source term models (cf. [3] and references therein). The program will evaluate the uncertainties introduced by parametric uncertainty, variations in environmental conditions, and the use of different conceptual models.

The present source term and near-field models in the Yucca Mountain performance assessment are believed to be conservative, but the uncertainties are large. To the extent that the mechanisms of release of specific radionuclides can be understood or the uncertainties decreased, the subsequent analysis of the far-field barriers becomes less important. In the present performance assessment, processes that will certainly occur, 
such as the formation of secondary, $\mathrm{U}^{6+}$-alteration phases, are not comprehensively coupled to controls on the release behavior of the other radionuclides. Also, very little performance credit is taken for the potential chemical interactions between released radionuclides and the alteration products of the SNF and metal waste packages or their internal components. The conservatism of the present models may be reduced by an improved understanding of the fundamental geochemical/hydrologic processes that will control the corrosion of SNF under oxidizing conditions and the potential interactions that may occur among the corroded SNF, the HLW-borosilicate glass, and the waste package components. This focused and integrated research program will also provide the scientific basis for the development of the next generation of more realistic models of source-term and near-field processes. Although there has been considerable research on the corrosion of spent nuclear fuel and nuclear waste glasses, there has been much less work on developing models that are applicable to an oxidizing environment, such as that at the Yucca Mountain repository. That said, this effort builds on the considerable amount of research on the corrosion of SNF (see [1] and references therein; [4] and references therein) and nuclear waste glasses (see [3] and references therein; [5]; [6] and references therein) that has already been completed.

Another important component of this program is the connection to international efforts, particularly of the European Community programs. Integration of the source term research program described here with the EU MICADO (Model uncertainty for the mechanism of dissolution of spent fuel in a nuclear waste repository) program is in progress. Through these collaborations, present U.S. funding can be leveraged for an increased understanding and enhanced international knowledge base available to the U.S. Program. International collaboration will also enhance technical understanding of the U.S. program in other countries.

\section{Scientific Approach and Research Program}

The nuclear waste forms, SNF, and nuclear waste glass, may serve different functions at different times in the multi-barrier system of a geologic repository. The waste form may be: 1) the sole barrier to release of radionuclides to the biosphere; 2) an effective, but not the primary, barrier to radionuclide release; 3.) a solid-medium for transportation and temporary storage [5]. At Yucca Mountain, the waste form is one of a series of barriers, engineered and geologic, to the release of radionuclides. The effectiveness of these barriers varies over time, as does the inventory of radioactive elements, the temperature, and the radiation field. Immediately after emplacement in a geologic repository, the waste forms are protected from contact with water by the waste package. During this time (hundreds to thousands of years), the waste forms experience the highest temperatures and radiation fields, but the waste forms are not in chemical contact with the surrounding geologic medium. The waste forms are only exposed to outside water after the waste package has been breached. At intermediate times (thousands to tens of thousands of years), some fraction of the waste packages will have failed, and the waste forms will be in contact with water, if only water vapor, and air. This represents the first possibility for release of radionuclides from the waste forms. At the longest time periods 
(tens of thousands to hundreds of thousands of years), most of the waste forms will be exposed to the ambient, geochemical/hydrological conditions. At this stage, one may expect extensive alteration of the waste form and hydrochemical interactions with corroded waste packages and the surrounding geology (cf. [7]).

In order to develop an integrated research program for the source term area, three different perspectives were adopted:

- To address the evolution of the waste form over time, three time intervals, that represent very different environmental conditions, were considered: $i$ ) The period of storage and immediately after disposal, but prior to breach of the waste package (tens to thousands of years); $i$ ) an early period after the breach of the waste package when temperature and radiation fields are still elevated (hundreds to thousands of years); iii) a later period after breach of the waste package when the thermal pulse and the radiation field return to nearly ambient conditions (after tens of thousands of years). Although these periods overlap, each time interval has distinctly different environmental conditions. Throughout these periods, the properties of the waste form change as a continuum in which the behavior at each interval depends on the prior condition of the waste form.

- For each time period, critical processes were identified that may affect waste form properties and control the release of radionuclides. Again, the important processes for each time interval depend on the environmental conditions (see Fig. 1).

- The radionuclide inventories for each waste form type change with time due to radioactive decay [8]. For each time interval, this means that the relevant processes and issues may be quite different. For the longer time periods, the radionuclide inventory is dominated by a more limited number of radionuclides, and the thermal and radiation fields are much reduced. For the purposes of the source term research program described here, the following radionuclides were identified as being potentially important to determining repository performance:

$$
{ }^{238} \mathrm{U},{ }^{235} \mathrm{U},{ }^{233} \mathrm{U},{ }^{239} \mathrm{Pu},{ }^{237} \mathrm{~Np},{ }^{241} \mathrm{Am},{ }^{129} \mathrm{I},{ }^{99} \mathrm{Tc},{ }^{79} \mathrm{Se} \text {, and }{ }^{36} \mathrm{Cl} .
$$

The above radionuclides were selected because most are identified as major contributors to potential dose as part of the Yucca Mountain Project Total System Performance Assessment (TSPA) process [9]. ${ }^{79} \mathrm{Se}$ and ${ }^{36} \mathrm{Cl}$ are listed because, while not identified as major dose contributors in the TSPA, their release may contribute significantly to dose estimates. ${ }^{241} \mathrm{Am}$ is selected because it is a parent of ${ }^{237} \mathrm{~Np}$, and the two $\mathrm{U}$ isotopes $\left({ }^{235} \mathrm{U}\right.$ and ${ }^{233} \mathrm{U}$ ) are fissile. Of course, ${ }^{238} \mathrm{U}$ is by far the most abundant radionuclide in $\mathrm{SNF}$ and will likely influence the release behaviors of other critical radionuclides.

By focusing on the changing conditions over time, identifying the processes within each time interval, and with attention to the radionuclides that are the major contributors to dose, the research program is able to improve fundamental understanding of source term 
processes. Moreover, this scientific framework is in the proper context to support development and elucidation of next-generation models for potential use in future performance assessments.

The source term research program is constructed to address the physical and chemical processes for each time interval (see Fig. 1 for portrayal of potential processes). For convenience the processes may be divided into two groups:

Prior to waste package failure:

- Development of the physical and chemical properties of SNF as a function of burn-up, temperature, fuel-type, storage/disposal conditions, and time

- Radiation-enhanced diffusion of radionuclides in SNF

- Oxidation of $\mathrm{UO}_{2}$ and the fate of radionuclides during phase changes/transitions

- Water- $\mathrm{UO}_{2}$ interactions

- Fuel-cladding interactions

- Microbial-waste form interactions

After waste package failure:

- Cladding failure mechanisms

- Release of gap radionuclide inventory

- Surface oxidation of $\mathrm{UO}_{2}$

- Matrix dissolution of $\mathrm{UO}_{2}\left(\mathrm{pH}, \mathrm{O}_{2}\right.$, temperature, flow-rate, solution composition, etc.)

- Dissolution and release of phases from grain boundaries and bulk $\mathrm{UO}_{2}$ (e.g., $\varepsilon$ phases)

- Radiolysis of solutions in contact with the SNF

- Complexation of radionuclides in solution

- Precipitation of $\mathrm{U}^{6+}$-phases and co-precipitation of radionuclides

- Radionuclide incorporation in secondary, alteration phases

- Sorption/desorption and reduction/"trapping" of radionuclides onto structural materials and their corrosion products

- Sorption/desorption and reduction/"trapping" of radionuclides onto near field geologic materials

- Formation and transport of colloids

- Radiation effects on secondary phases

- Microbial-waste form interactions

For any specific radionuclide, the relevant processes may be summarized according to their release pathway (Fig. 2). The release pathways summarize the sequence of processes that may lead to release (or retardation) of each radionuclide.

The above scientific framework allowed for formulation of a research program that addresses many of the physical and chemical processes described above. In addition, the concept of release pathways for key types of radionuclides provided additional insights in framing the program. The present program, summarized below, consists of fifteen 
separate programs that involve five U.S. national laboratories and five universities (one in Great Britain). In many instances, university investigators have programs closely tied to national laboratories in order to utilize unique facilities for handling highly radioactive materials.

The current research programs address four key areas:

1) SNF dissolution mechanisms and rates: The initial release of radionuclides is governed by the specific mechanisms and rates of dissolution, which in turn, vary as a function of $\mathrm{pH}$, dissolved oxygen concentration, temperature, solution composition, fuel chemistry (i.e., burn-up), and mode of contact with water. Systematic studies are being conducted of radionuclide release from SNF as a function of these parameters, with special attention being paid to the effects of radiolysis on matrix dissolution rates and the formation of secondary phases. The program also investigates the effects of water that may condense and accumulate on failed spent fuel pins. By the process of deliquescence of hygroscopic fission product phases, alteration products may form on the surfaces of the SNF.

2) Formation and properties of U(VI)-secondary phases: Under an oxidizing environment, the corrosion of SNF leads to the formation of a complicated array of U(VI)-secondary phases that may retard release of radionuclides either by coprecipitation/incorporation, sorption or by forming a physical barrier to the continued contact with water or release of radionuclides. A multi-pronged approach was developed that includes carefully controlled experiments to determine the means and extent of radionuclide incorporation (e.g., ${ }^{237} \mathrm{~Np},{ }^{239} \mathrm{Pu}$, and ${ }^{129} \mathrm{I}$ ) and sorption into and onto the structures of $\mathrm{U}(\mathrm{VI})$-secondary phases. The experimental work is supported by the application of advanced techniques (x-ray absorption spectroscopy at the Advanced Photon Source, laser-ablation inductively coupled plasma mass spectroscopy, and in situ spectroelectrochemical techniques) in order to determine the extent of incorporation and sorption of radionuclides in/on U(VI)-secondary phases. The stability of these phases is being determined by high-temperature oxide melt solution calorimetry and reversible solubility measurements, as well as systematic irradiation experiments. Computational simulations involving quantum mechanical calculations are being used to investigate the energetics of the incorporation and sorption processes. In addition, actinide complex stability constants at elevated temperatures are being measured using potentiometry, solvent extraction, spectrophotometric and nuclear magnetic resonance measurements. The experimental and modeling studies are being supported and confirmed by studies of natural occurrences of SNF, for example at the Oklo natural reactors.

3) Waste form - waste package interactions in the near-field: The SNF will corrode and release radionuclides in an environment dominated by the presence of uranium, iron, and solutions whose compositions are the result of interactions with the waste forms, waste packages, and the surrounding volcanic tuff. These interactions buffer the environment in which the SNF corrodes and also offer additional opportunities for reduced mobility of radionuclides. Research programs were developed to investigate the types and behaviors of waste package corrosion products, and their potential for reduction and sorption of key 
radionuclides (e.g., uptake of ${ }^{99} \mathrm{Tc}$ onto iron oxyhydroxides). The research programs are also focusing on the interactions of $\mathrm{UO}_{2}$ with solutions in contact with volcanic tuff using the pressurized unsaturated flow (PUF) system and in situ analytical techniques to investigate and characterize the secondary phases that form. Again, computational simulations of atomic-scale interactions will be used to interpret and support the experimental results.

4) Integration of in-package chemical and physical processes: The greatest challenge for this program is to integrate the scientific results into a larger scale model of source term and near-field interactions. In order to accomplish this, numerical models are being developed that capture the important physical and chemical processes that lead to radionuclide release from SNF. The source term model will be coupled to a drift/near field-scale model that captures the relevant thermal-hydrologic-chemical regimes as a function of time. This integrated model will provide a basis for understanding source term behavior at different time frames, as described above.

\section{Discussion and Conclusions}

A closed fuel cycle requires a geologic repository to dispose of long-lived fission products and potentially very small amounts of actinides, the latter being from minor separations process losses. The potential waste form materials-oxides, glasses, and/or metals - containing the radionuclides are a key component of the repository system. The potentially significant doses from the encased radionuclides require long-term isolation in durable waste forms. As part of efforts in the U.S. and worldwide to develop advanced nuclear fuel cycles for the future, additional research is required to identify potential advanced waste form materials (cf. [3] and references therein). If candidate advanced waste form materials are further developed, focused work to further understanding of waste form performance in complex geologic settings is needed. Demonstration of geologic repository performance to $10^{4}$ years (and even $10^{6}$ years), and the role of the source term in long-term safety, represents an unprecedented scientific challenge.

To provide durable waste forms and demonstrate their long-term performance, the behavior of materials must be understood at a level of fundamental knowledge and predictability that could allow for reduction in the conservatism of engineered system designs, while still achieving the required safety margins, and perhaps lowering repository costs. The waste form materials form complex multi-component dynamic systems that evolve in time under a wide range of conditions including high radiation fields, high temperatures, and potentially corrosive chemical environments (see [3] and references therein; [10]). Fundamental understanding of the properties of waste forms is essential to predicting their long-term behavior and can only come about through closely coupled theory, modeling, and experimentation.

In summary, a fundamental and integrated experimental and modeling approach to source term processes, as described above for SNF, can also be readily applied to development of advanced waste forms as part of a closed nuclear fuel cycle. Specifically, a 
fundamental understanding of candidate advanced waste form materials stability in high temperature/high radiation environments and near-field geochemical/hydrologic processes could enable development of waste forms "tailored" to specific geologic settings (cf. [3]). The development of these "tailored" waste forms would also be contingent on an integrated analysis of the closed nuclear fuel cycle. Such a systems analysis would allow for optimization of the entire separations/storage/disposal process. The key elements are to develop the optimal separations process to minimize separations process losses, while producing the required product form for advanced nuclear fuel fabrication and storage form for short-lived fission products, and finally, waste forms tailored to specific geologic settings.

\section{Acknowledgments}

The authors would like especially to thank the scientists involved in source term research in the Office of Science and Technology and International for their insights that helped guide the development of the research program, and also would like to thank Abe VanLuik, David Sassani, and an anonymous reviewer for comments on an earlier version of this manuscript. This work was supported in part by the United States Department of Energy, Office of Civilian Radioactive Waste Management, Office of Science and Technology and International (DOE/OCRWM/OST\&I). The views, opinions, findings, and conclusions or recommendations of authors expressed herein do not necessarily state or reflect those of the DOE/OCRWM/OST\&I. 


\section{References}

[1] B. Grambow, A. Loida, A. Martinez-Esparza, P. Diaz-Arcoas, J. De Pablo, J-L Paul, G. Marx, J-P Glatz, K. Lemmens, K. Ollila, H. Christensen, Source Term for Performance Assessment of Spent Fuel as a Waste Form. European Commission Report, Nuclear Science and Technology, EUR 19140 (2000) 356 pp.

[2] C. Poinssot, P. Toulhoat, J-P. Grouiller, J. Pavageau, J-P. Piron, M. Pelletier, P. Dehaudt, C. Cappelaere, R. Limon, L. Desgranges, C. Jegou, C. Corbel, S. Maillard, M-H. Faure, J-C. Cicariello, M. Masson, Synthesis on the Long Term Behavior of the Spent Nuclear Fuel. vol. I and II, Report CEA-R-5958 (2001) 616 pp.

[3] W. Lutze, R.C. Ewing, Radioactive Waste Forms for the Future. North-Holland, Amsterdam (1988) $778 \mathrm{pp}$.

[4] D.W. Shoesmith, M. Kolar, F. King, Corrosion, 59 (2003) 802-816.

[5] National Research Council, Glass as a Waste Form and Vitrification Technology. National Academy Press, Washington, D.C. (1996) 108 pp.

[6] P. Van Iseghem, J. Nucl. Mater., 298 (2001) 1-202.

[7] C.J. Allan, K. Nutall, Nucl. Eng. Design, 176 (1997) 51-66.

[8] A. Heden, Spent Nuclear Fuel - How Dangerous is it? SKB Report 97-13 (1997) 60 pp.

[9] BSC, Radionuclide Screening. ANL-WIS-MD-000006 REV 01, Bechtel SAIC Company, Las Vegas, Nevada (2002).

[10] K.L. Smith, G.R. Lumpkin, M.G. Blackford, R.A. Day, K.P. Hart, J. Nucl. Mater., 190 (1992) 287-294. 


\section{Figure Captions}

Figure 1. Schematic illustration of the potentially important processes used as a framework for definition of the source term research program. Epsilon phase represents Mo-rich metallic particles that occur in spent nuclear fuel and are known to contain appreciable amounts of Tc.

Figure 2. Radionuclide release pathways for important types of radionuclides used as a framework for definition of the source term research program. 
Figure 1.

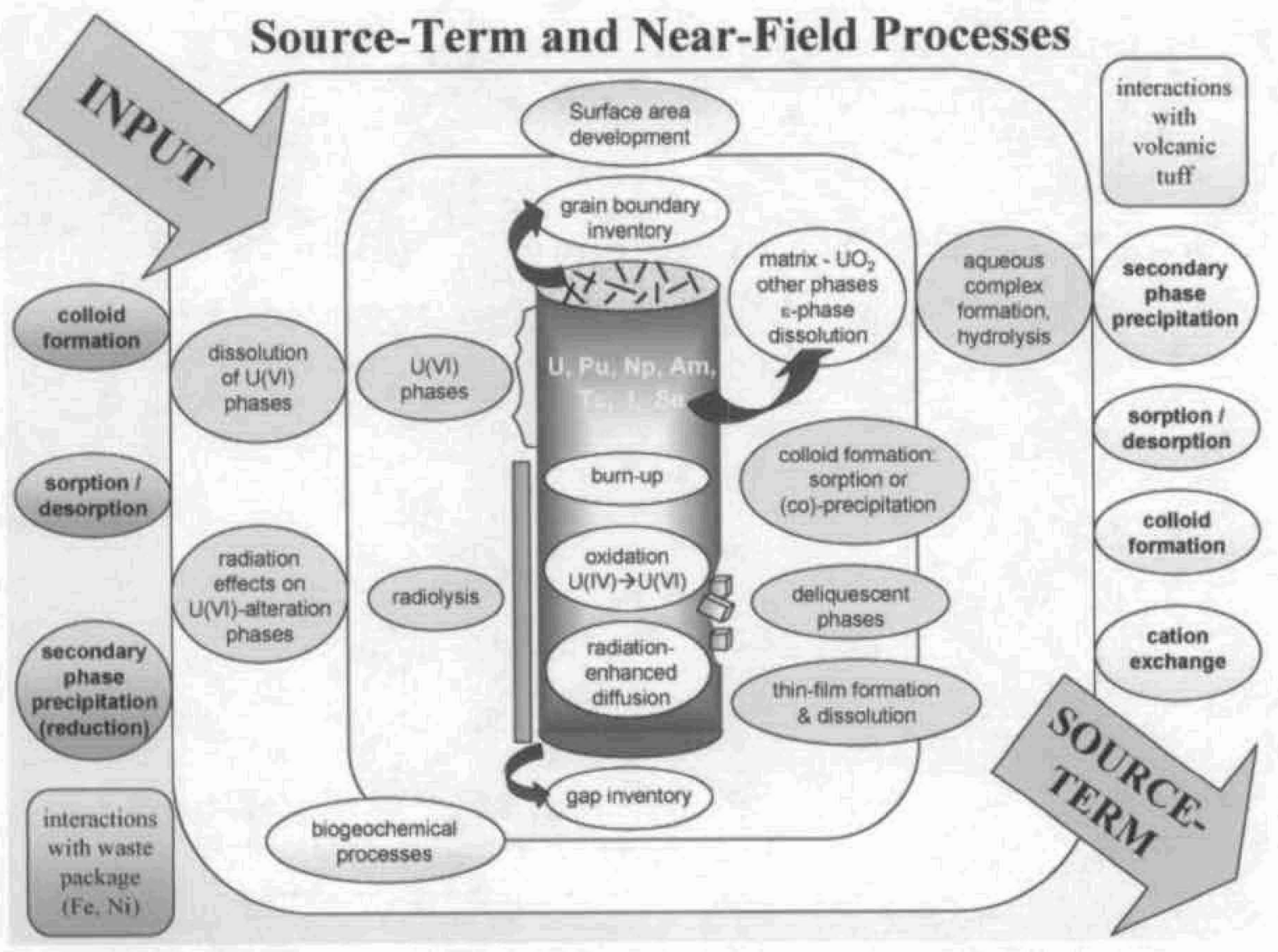


Figure 2.

\section{Pathway to Release for Actinides $\left({ }^{237} \mathrm{~Np},{ }^{239} \mathrm{Pu},{ }^{241} \mathrm{Am}\right)$}

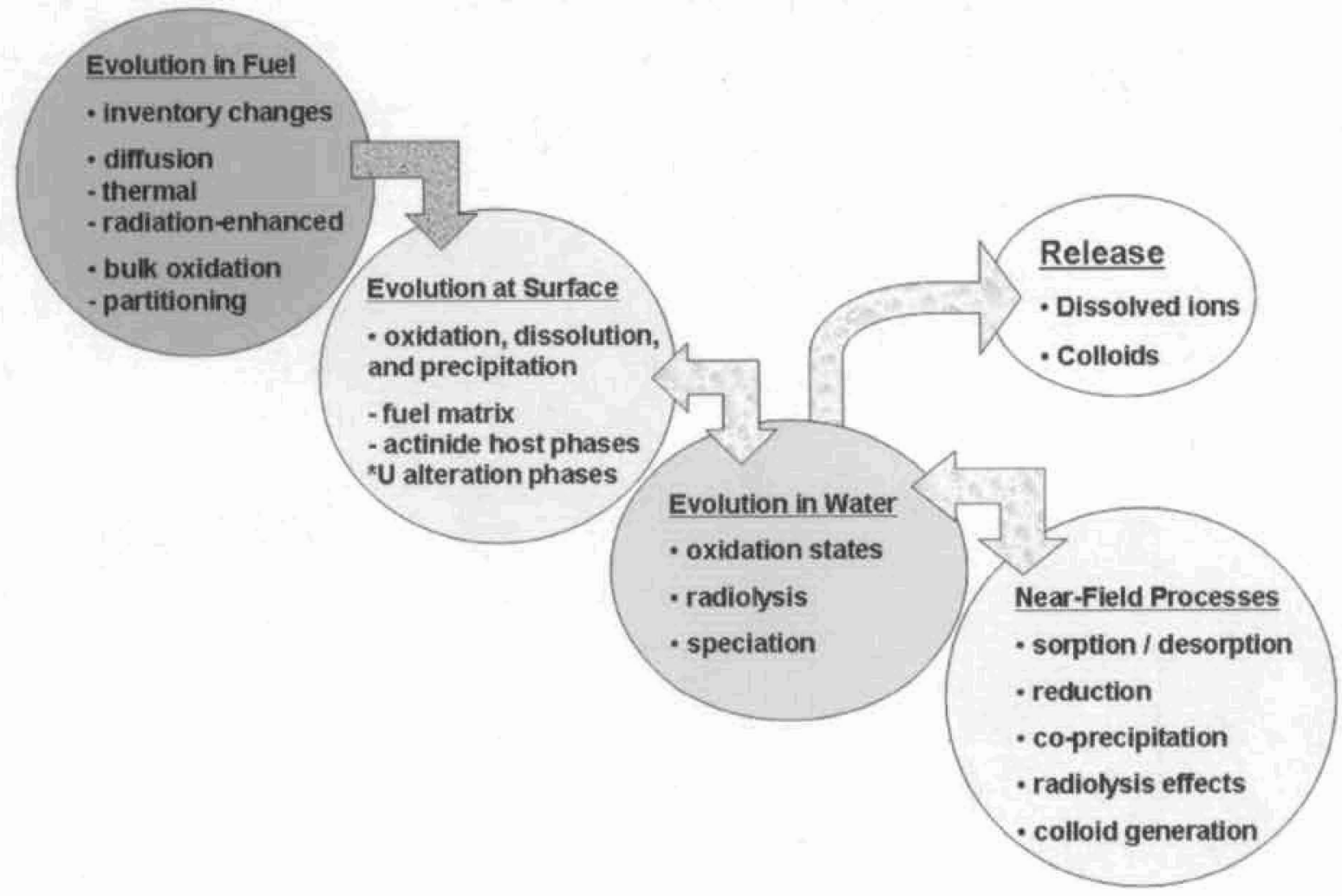




\section{Pathway to Release for Fission Products $\left({ }^{99} \mathrm{Tc}\right)$}

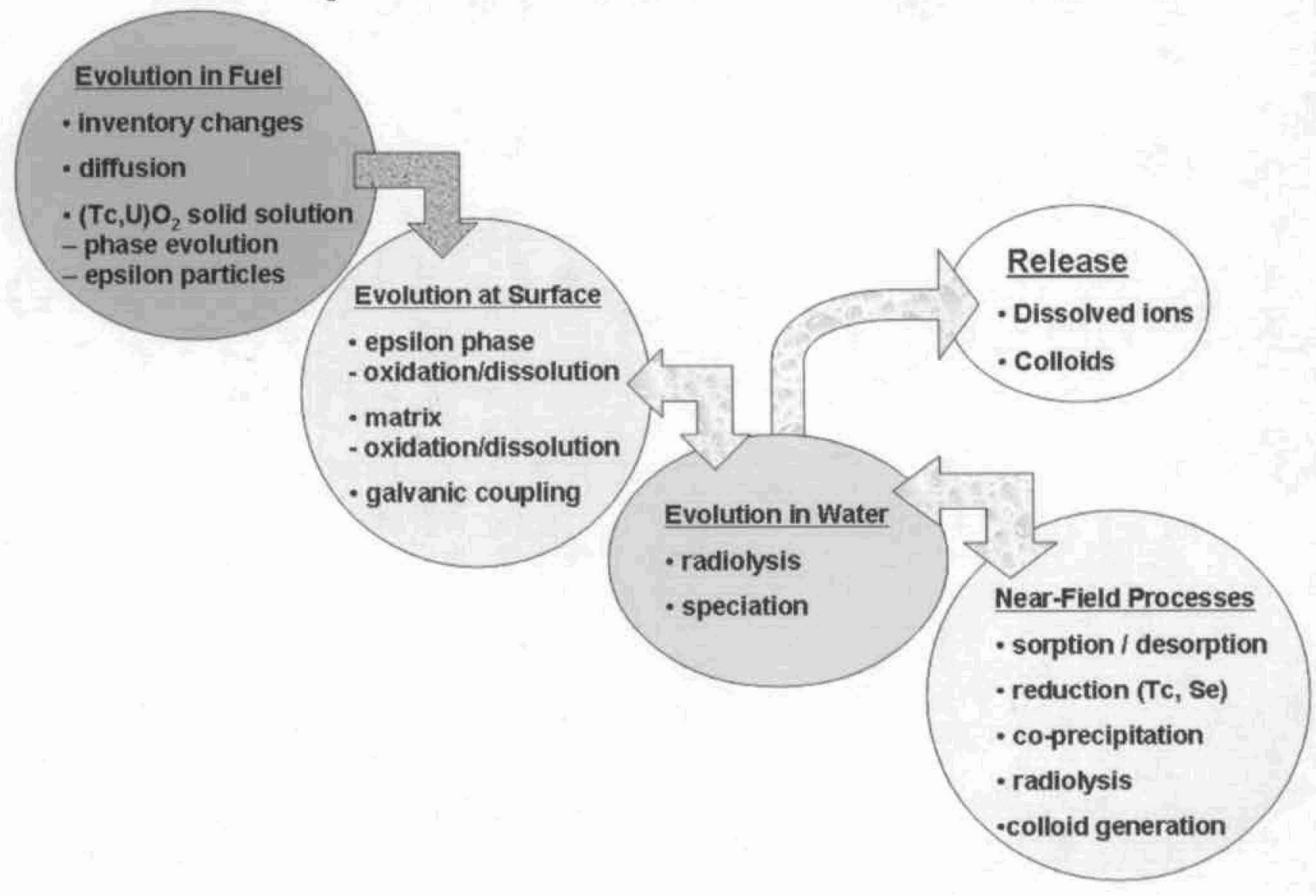




\section{Pathway to Release for Fission Products $\left({ }^{129} I\right)$}

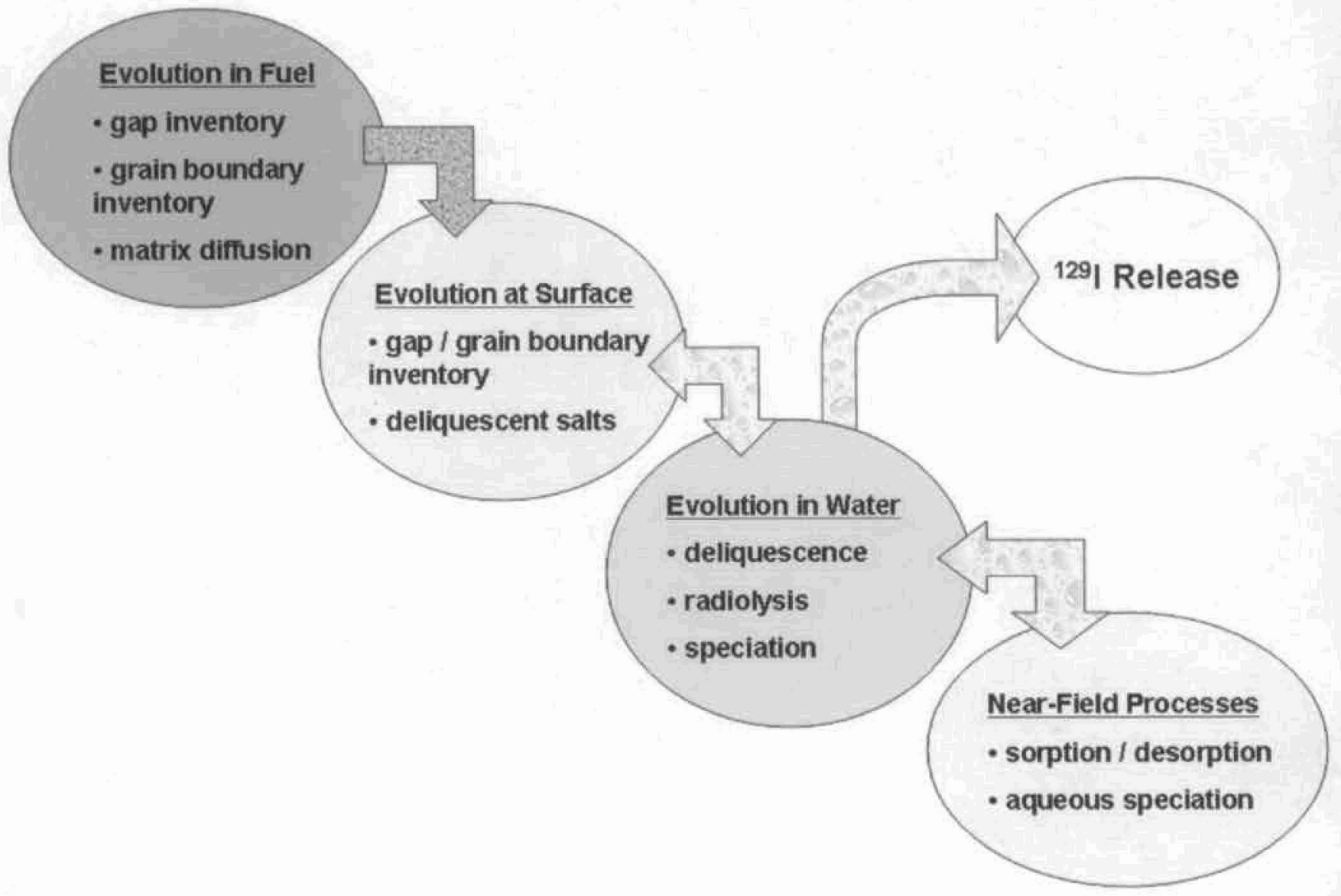

